\title{
Socio-economic status and hunger among orphans and vulnerable children households in Lagos State, Nigeria
}

\author{
Elijah Bamgboye ${ }^{1}$, Tayo Odusote ${ }^{2}$, Iyabode Olusanmi ${ }^{1}$, Joshua Akinyemi ${ }^{3}$, Yussuf Bidemi ${ }^{3}$, \\ Ayo Adebowale ${ }^{3,4}$, Ashaolu Gbenga ${ }^{1}$, Oladapo Ladipo ${ }^{1}$
}

1. Association for Reproductive and Family Health.

2. USAID.

3. University of Ibadan College of Medicine, Epidemiology and Medical Statistics.

4. University of Cape Town, Actuarial Research.

\begin{abstract}
Background: HIV/AIDS has contributed to increasing orphans and vulnerable children in Nigeria. A measure of vulnerability is household hunger.

Objective: To assess level of household hunger and associated factors among OVC households in Lagos State.

Methods: A cross-sectional survey of 1300 OVC households in 5 selected Local Government Areas. The LGAs were selected using the Household Vulnerability Assessment index. Data collection was by personal interview of households' heads/ caregivers using a structured questionnaire capturing socio-demographic, household economic profile and food-related variables. A multivariate logit model was fitted to identify independent predictors of household hunger after adjusting for confounding variables.

Results: The population density was 5.1 and $52.8 \%$ were females. A larger proportion of females (84.6\%) than males $(78.3 \%)$ reported that they had no food to eat in the last four weeks prior the survey. Poor household economic status $(\mathrm{OR}=1.41, \mathrm{CI}: 1.03-1.92)$, age and marital status of caregiver were independent predictors of household hunger. The odds of hunger increased with caregiver's age; higher in households headed by never married (OR=3.99, CI: 1.15-13.89) and divorced/separated caregivers (OR=2.39, CI: 1.11-5.12).

Conclusion: OVC households experienced severe hunger. Household economic strengthening would be useful strategy to mitigate the nutrition challenges of OVC in Lagos state.

Keywords: Orphans, vulnerable, children, households food security, caregivers, economy, Nigeria.

DOI: https://doi.org/10.4314/ahs.v20i2.47

Cite as: Bamgboye E, Odusote T, Olusanmi I, Akinyemi J, Bidemi Y, Adebowale A, et al. Socio-economic status and hunger among orphans and vulnerable children bouseholds in Lagos State, Nigeria. Afri Health Sci. 2020; 20(2): 923-931. https:/ / doi.org/ 10.4314/abs.v20i2.47
\end{abstract}

\section{Background}

According to the Nigeria Federal Ministry of Women Affairs and Social Development (FMWASD), an orphan is a child (0-17 years) who has lost one or both parents and such an orphan is vulnerable if he/she is prone to abuse or deprivation of basic needs, care, and protection as a result of his/her immediate circumstances or environment ${ }^{1}$. Poor economic situation and the HIV epidemic have contributed largely to the high burden

\section{Corresponding author: \\ Elijah Bamgboye, Association for Reproductive and Family Health Odusote, Tayo USAID \\ Email: bamelijah@gmail.com}

of Orphans and Vulnerable children (OVC) in Nigeria ${ }^{2}$. The prevalence of HIV in Nigeria estimated as 3.4\% may appear low superficially but when we consider that Nigeria has a population of over 170 million people, it translates to a high number of adults and children. In fact, the Federal Ministry of Health in Nigeria estimated that there are more than 2.5 million orphans due to AIDS2, This number must have increased by now because the advantage of the availability of antiretroviral treatment has been hampered by inadequate coverage and sub-optimal uptake of Prevention of Mother-toChild Transmission of HIV ${ }^{1,3}$, Recently, the President's Emergency Plans for AIDS Relief (PEPFAR) modified the definition of OVC as a child (0-17 years) who is either orphaned or made vulnerable by HIV/AIDS to put OVC in its front burner. 
The advent of HIV epidemics in the early 1990s and the attendant mortality before availability of antiretroviral drugs left many households without breadwinners1. As a result, many households suffer material deprivation which is one of the consequences of AIDS mortality ${ }^{5}$. The immediate effect of household deprivation often manifest in non-availability of food which leads to hunger. Apart from hunger, there are other negative outcomes that affect households orphaned by HIA/AIDS. These include childhood morbidity 3 , incomplete immunization 4, poor nutritional status and other forms of negative cognitive developmental deficiencies ${ }^{6}$.

Many of the studies on food in HIV-affected households linked hunger with the demise of one or both parents of HIV affected or infected children. Perhaps, as a reflection of the geography of HIV in Sub-Saharan Africa, most of the evidence on OVC has been from Eastern and Southern Africa. An Ugandan study reported regional differences and female preponderance on the issue of access to education among OVC5. Also, a situational analysis survey in Kenya found that OVC had awide range of problems including poor self-rated health and inadequate access to food and water ${ }^{7}$. Similar problems associated with socio-economic challenges have been reported among OVC in Cameroon and Rwanda ${ }^{8,9}$.

Nigeria has one of the largest populations of persons living with HIV in the world10. By implication, the population of OVCs is also one of the largest. The most notable source of evidence on OVC is the Nigeria Demographic and Health Survey (NDHS) and Multiple Indicator Cluster survey (MICS). The NDHS 2013 reported that $95 \%$ of OVC do not receive any type of medical, emotional, social, material or any school-related assistance ${ }^{10}$. A recent study in Plateau state, Nigeria also identified food and shelter, education, health care, protection and poor household economy as the most critical needs of $\mathrm{OVC}^{11}$.

The previous interventions to mitigate OVC challenges in Nigeria have largely been donor- driven and the strategies can simply be described as giving 'hand outs' which in general have not been sustainable. This is so because as soon as the donor financial support stops, the support to OVC also stops. The national plan of action for OVC coordinated by the FMWASD in Nigeria with support from several international donor partners, have produced very negligible outcomes ${ }^{1}$. Recently, the United States Agency for International Development
(USAID) through its PEPFAR program introduced a new paradigm shift in its support for OVC and mitigation of the impacts of HIV/AIDs in Nigeria. This is aimed at economic strengthening of caregivers in households with OVC to ensure better care for them4. It also planned to improve the systems and structures for the provision of OVC services, at State, Local Government Area (LGA) and Community levels. The core components of OVC services in this new agenda were education, health, nutrition, shelter, protection, psychosocial support and strengthening the economic capacity of caregivers.

In the process of implementing this project in Lagos State, Nigeria, a baseline survey was conducted in selected LGAs in accordance with PEPFAR guidelines. Lagos, the most populous and commercial nerve centre of Nigeria has a fair share of the growing population of OVC in the country. We analyzed data from the baseline survey in Lagos state to explore the critical issue of social-economic status and household hunger. Specifically, the three-fold objective of this paper are:

(i) To estimate the magnitude of household hunger among OVC in Lagos State,

(ii) To determine the relationship between economic status and household hunger;

(iii) To describe the association of demographic characteristics of caregivers and economic status to household hunger.

\section{Methodology}

A cross sectional baseline survey of OVCs and their caregivers in 5 LGAs in Lagos State, Nigeria was carried out in February 2015. The LGAs were purposefully selected based on USAID guidelines (the agency providing the funding for this OVC intervention project) dictated by the burden of HIV and non-presence of other implementing partners in the LGAs. The LGAs are Agege, Ajeromi, Ojo, Badagry and Kosofe. The wards were selected using a cluster sampling technique; all political wards in each of the LGAs constituted natural clusters. The National Vulnerable Assessment Questionnaire was administered to every household in each selected ward or cluster. The index of vulnerability was determined by scores obtained on this questionnaire which categorized as: most vulnerable households with score of 21-28 points, more vulnerable scores of 14- 20 points and vulnerable scores of $7-13$ points based $\mathrm{n}$ a 4-point scale of ratings on household headship, health, education, shelter, housing, food security \&Nutrition and means of livelihood and household income. All 
households that fell into the 'Most Vulnerable' category and all the 'more vulnerable' were numbered and listed for the baseline survey. A sample of 1,300 households constituting $10 \%$ of all households to be enrolled in the first year of the 5-year project period was considered adequate for the baseline survey. The households was selected by systematic sampling technique using one (1) in every 5 selected households.

\section{Data collection}

A standard, structured questionnaire adapted from Measure Evaluation and the national child vulnerability index form12 was used to collect information on socio demographic characteristics, and items relating to the seven key service areas: of economy, education, food security, shelter, health, protection, psychosocial, care and support. The questionnaire was subdivided into three separate sections vis-a-vis caregiver/household information, children 0-9 years and children 10-17 years. The questionnaires were interviewer- administered by well-trained research assistants/interviewers/ supervisors. The interviewers and supervisors were carefully selected so that they are culturally acceptable, have good knowledge of the local language and relevant experience in household surveys. Data analyzed in this paper were those collected from OVC caregivers in the selected households.

\section{Variables in data analysis}

The dependent variable in this study was household hunger. Household hunger was determined from responses to the question: In the past 4 weeks, 'did you go a whole day and night without eating anything because there was not enough food to it? A 'Yes' answer signifies "presence of household hunger", while 'No' signifies "absence". The main independent variable was household socio-economic status while other background characteristics of the OVC caregiver or household head (sex, age, level of education, duration of stay in residence, literacy level, working status, marital status, and religion) served as control variables.

\section{Measurement of household socio-economic status}

The household economic status was derived using the following 7 questions

1. Do you usually work throughout the year, or do you work seasonally, or only once in a while?

2. Are you paid in cash or work?

3. Was your household able to pay for any food-related expenses?
4. Was your household able to pay for any school-related expenses?

5. Thinking about the last time you bought any food for eating or cooking, where did the money come from? 6. Thinking about the last time you had to pay for any school-related expenses, where did the money come from?

7. Was your household able to pay for any unexpected household expenses such as house repair or urgent medical treatment in the last 12 months?

Scores of 0 and 1 were assigned to each item if the respondent gave a "no" or "yes" to questions 1, 2, 3, 4 and 7. However, for questions 5 and 6 , score of 1 was assigned if the respondent mentioned "income" or 0 if otherwise. The categories of poor and good economic status were derived by using the median (4.0) score as cut-off point. Households with scores below the cutoff were categorized has having poor economic status while those with scores greater than or equal to 4 were classified as good economic status.

\section{Statistical analysis}

Descriptive statistics such as means, medians, standard deviations, and ranges were used to summarize quantitative variables while categorical variables were summarized with percentages. The Chi square test was used to examine the significance between any two qualitative variables. The multivariate logistic regression model was fitted to explore the relationships between household economic status, background characteristics of caregivers/ household head and household hunger. Chisquare test was used to test for the goodness of fit of the model, the level of significance was set at $5 \%$ while the effect of Va riables were expressed as Odds Ratio (OR) with their 95\% confidence intervals. A variable with OR $>1.00$ was interpreted as positively associated with household hunger while variables with $\mathrm{OR}<1.00$ were deemed to be negatively associated.

\section{Results}

\section{Socio demographic characteristics of caregivers}

A total of 6,669 people resided in the 1,300 households for which information was available in this survey which gave a household density of 5.1. There was a slight female preponderance as $53 \%$ were females and a higher proportion of household heads or caregivers were females $(73 \%)$. The mean age of the household heads was $43.1 \pm 13.9$ years. 
Table 1: Socio-demographic characteristics of OVC caregivers by sex

\begin{tabular}{|c|c|c|c|}
\hline \multirow[t]{2}{*}{ Socio-demographic characteristics } & Sex & \multirow[b]{2}{*}{ Female } & \multirow[b]{2}{*}{ Total } \\
\hline & Male & & \\
\hline \multicolumn{4}{|l|}{ Age of caregiver } \\
\hline Less than $24^{\circ}$ & $8(2.2)$ & $41(4.4)$ & 49 \\
\hline $25-29$ & $22(6.2)$ & $118(12.5)$ & 140 \\
\hline $30-34$ & $53(14.9)$ & $164(17.4)$ & 217 \\
\hline $35-39$ & $58(16.3)$ & $145(15.4)$ & 203 \\
\hline $40-44$ & $63(17.7)$ & $126(13.4)$ & 189 \\
\hline $45-49$ & $34(9.6)$ & $86(9.1)$ & 120 \\
\hline $50-54$ & $40(11.2)$ & $78(8.3)$ & 118 \\
\hline $55-59$ & $22(6.2)$ & $51(5.4)$ & 73 \\
\hline 60 and above & $56(15.7)$ & $132(14.0)$ & 188 \\
\hline Total & $356(100)$ & $941(100)$ & 1297 \\
\hline \multicolumn{4}{|l|}{ Highest level of education } \\
\hline Never attended school & $32(9.0)$ & $240(25.5)$ & 272 \\
\hline Quranic education & $11(3.1)$ & $23(2.4)$ & 34 \\
\hline Primary & $106(29.9)$ & $273(29.0)$ & 379 \\
\hline Secondary & $179(50.4)$ & $384(40.8)$ & 563 \\
\hline Tertiary & $27(7.6)$ & $21(2.2)$ & 48 \\
\hline Total & $355(100)$ & $941(100)$ & 1296 \\
\hline \multicolumn{4}{|l|}{ Duration of stay in residence (yrs) } \\
\hline $0-9$ & $163(46.3)$ & $463(49.2)$ & 626 \\
\hline $10-19$ & $109(31.0)$ & $238(25.3)$ & 347 \\
\hline $20-29$ & $29(8.2)$ & 131(13.9) & 160 \\
\hline $30-39$ & $22(6.2)$ & $55(5.8)$ & 77 \\
\hline 40 and above & $29(8.2)$ & $54(5.7)$ & 83 \\
\hline Total & $352(100)$ & $941(100)$ & 1293 \\
\hline \multicolumn{4}{|l|}{ Literacy status } \\
\hline Cannot read at all & $84(23.7)$ & $462(49.3)$ & 546 \\
\hline Able to read parts of a sentence & 104(29.3) & $238(25.4)$ & 342 \\
\hline Able to read whole sentence & $155(43.7)$ & $221(23.6)$ & 376 \\
\hline No card with language & $5(1.4)$ & $16(1.7)$ & 21 \\
\hline Blind/Visually impaired & $7(2.0)$ & $0(0.0)$ & 7 \\
\hline Total & $355(100)$ & $937(100)$ & 1292 \\
\hline \multicolumn{4}{|l|}{ Marital status } \\
\hline Married & $276(77.5)$ & $412(43.7)$ & 688 \\
\hline Cohabiting & $21(5.9)$ & $87(9.2)$ & 108 \\
\hline Never married & $11(3.1)$ & $23(2.4)$ & 34 \\
\hline Divorced/separated & $12(3.4)$ & $84(8.9)$ & 96 \\
\hline Widowed & $36(10.1)$ & $337(35.7)$ & 373 \\
\hline Total & $356(100)$ & $943(100)$ & 1299 \\
\hline \multicolumn{4}{|l|}{ Religion } \\
\hline No religion & $3(0.8)$ & $1(0.1)$ & 4 \\
\hline Christianity & 201(56.6) & $524(55.5)$ & 725 \\
\hline Islam & $151(42.5)$ & $419(44.4)$ & 570 \\
\hline Total & $355(100)$ & $944(100)$ & 1299 \\
\hline
\end{tabular}

Table 1 showed the socio-demographic characteristics of caregivers by their sex. Difference in age distribution among the sexes was not substantial with $15 \%$ females in the 35-39 years category compared to $16 \%$ of the males. In addition, $14 \%$ of the females were older than 60 years compared with $16 \%$ of males.

About a quarter of the females $(26 \%)$ had never attended school, while $41 \%$ had secondary education. However, about half $(50 \%)$ of the males attained secondary level of education. A larger proportion of the males (78\%) was married compared to only $44 \%$ of the females. And, while $10 \%$ of the males were widowed it was more than a third (36\%) among females. Less than half of the respondents (males: $46 \%$ vs females: $49 \%$ ) had lived in their usual residence for 10 years or less.
About half $(49 \%)$ of the females could not read at all compared to only $24 \%$ of males. But a higher proportion $(44 \%)$ of the males could read a whole sentence compared to only $24 \%$ of females.

\section{Household economic status}

Table 2 showed the frequency distribution of household economic characteristics by sex of caregiver. Work profile of both male and female caregivers were not different as more than half worked throughout the year (male: 56\%, female: $60 \%$ ) and majority received cash for the work done. A high proportion of respondents (males: 86\%, females: 88\%) incurred food expenses sometime in the last four weeks and were able to pay for these expenses using money from their current income 
(males: 70\%, females: $73 \%$ ). A large proportion also (males: $85 \%$ and females: $87 \%$ ) incurred school related expenses in the last four weeks and a good proportion were not able to pay for these expenses (males: $62 \%$ and females: 64\%). The source of money for food expenses was mainly from current income (males: $77 \%$, females:
$74 \%$ ) while less than five percent got loans (males: $3 \%$, females $5 \%$ ). Similarly, their source of money for school expenses was mainly from current income (males: $71 \%$, females: 66\%) while $6 \%$ depended on loans similar in males and females head of households. Overall, less than half $(46 \%)$ had poor household economic status.

Table 2: Frequency Distribution of Household Economic Characteristics by Sex of caregiver

\begin{tabular}{llll} 
Household Economic Characteristics & \multicolumn{2}{c}{ Sex } & Total \\
\cline { 2 - 3 } & \multicolumn{1}{c}{ Male } & Female & \\
\hline Work Status & & & 689 \\
Throughout the year & $184(56.3)$ & $1905(59.6)$ & 273 \\
Seasonally & $83(25.4)$ & $153(18.0)$ & 213 \\
Once in a while & $60(18.3)$ & $848(100)$ & 1175 \\
Total & $327(100)$ & & 1009 \\
Work payment & & $727(88.0)$ & 100 \\
Cash only & $282(85.7)$ & $70(8.5)$ & 20 \\
Cash and kind & $30(9.1)$ & $10(1.2)$ & 26 \\
In kind only & $10(3.0)$ & $19(2.3)$ & 1155 \\
Not paid & $7(2.1)$ & $826(100)$ & 1129 \\
Total & $329(100)$ & & 165 \\
Incurring food related expenses & & $824(87.6)$ & 1294 \\
Yes & $305(86.4)$ & $117(12.4)$ & 841 \\
No & $48(13.6)$ & $941(100)$ & 325 \\
Total & $353(100)$ & & 1166 \\
Ability to pay for food expenses & & $618(73.0)$ & \\
Yes & $223(69.9)$ & $229(27.0)$ & 1120 \\
No & $96(30.1)$ & $847(100)$ & 175 \\
Total & $319(100)$ & $821(87.2)$ & 1295 \\
Incurring any school related expenses & & $120(12.8)$ & \\
Yes & $299(84.5)$ & $941(100)$ & \\
No & $55(15.5)$ & &
\end{tabular}

\section{Household hunger}

A larger proportion of females (85\%) than males $(78 \%)$ reported that they had no food to eat in the last four weeks as shown in Table 3. Also, a higher proportion of the females $(79 \%)$ than males $(69 \%)$ reported that household members had gone to sleep at night hungry.
In comparison with other households, a higher proportion of female caregivers $(41 \%)$ rated their conditions worse than their male counterparts $(32 \%)$ Table 4 showed that household hunger increased with age of caregiver and was highest among caregivers who attended primary school $(90 \%)$, and those who were never married (97\%). 
Table 3: Frequency Distribution of OVC Household hunger by sex of caregivers

\begin{tabular}{lccl}
\hline Measures of household hunger & \multicolumn{3}{l}{ Sex } \\
\hline \multicolumn{1}{l}{ No food to eat in the past four weeks } & Male & Female & Total \\
Yes & $278(78.3)$ & $797(84.6)$ & 1075 \\
No & $77(21.7)$ & $145(15.4)$ & 222 \\
Total & $355(100)$ & $942(100)$ & 1297 \\
Household went to sleep at night & & & \\
hungry & $240(69.4)$ & $738(78.9)$ & 978 \\
Yes & $106(30.6)$ & $197(21.1)$ & 303 \\
No & $346(100)$ & $935(100)$ & 1281 \\
Total & $124(35.5)$ & $374(40.3)$ & 498 \\
Any household member go day and night without food & $555(59.7)$ & 780 \\
Yes & $225(64.5)$ & $929(100)$ & 1278 \\
No & $349(100)$ & & \\
Total & & $41(4.4)$ & 79 \\
Comparison with other households & $38(10.9)$ & $141(15.1)$ & 207 \\
Much better than other household & $66(18.9)$ & $370(39.7)$ & 504 \\
A bit better than other household & $134(38.4)$ & $273(29.3)$ & 358 \\
About the same as other household & $85(24.4)$ & $107(11.5)$ & 133 \\
A bit worse than other household & $26(7.4)$ & $932(100)$ & 1281 \\
Much worse than other household & $349(100)$ & \\
Total & &
\end{tabular}

Economic status, caregiver characteristics and household hunger

The results of the logistic regression model fitted to identify the independent factors associated with household hunger are presented in Table 4. Univariate models showed that there were statistically significant associations between household economic status, sex, age, level of education, literacy status, marital status of OVC caregivers and household hunger $(\mathrm{P}<0.05)$. The odds of household hunger was $76 \%$ higher in household with poor economic status $(\mathrm{OR}=1.76, \mathrm{CI}$ : 1.072.87). Households headed by female caregivers were 1.7 times more likely to experience hunger than those headed by male caregivers. The odds of household hunger increased with age of caregiver from 30-34 years
$(\mathrm{OR}=2.10, \mathrm{CI}: 0.70-6.31)$ to $50-54$ years $(\mathrm{OR}=5.38, \mathrm{CI}$ : 1.26-23.02). Also, households in which caregivers had secondary education $(\mathrm{OR}=0.42, \mathrm{CI}$ : $0.17-1.06)$ and tertiary education $(\mathrm{OR}=0.60, \mathrm{CI}: 0.13-2.68)$ were less likely to suffer from hunger compared to those households whose caregivers never attended school. Compared to households with caregivers who are married, all in other categories of marital status had higher odds of hunger except the widowed who had a lower odds of hunger. Multivariate models fitted to adjust for confounding variables showed that the independent predictors of household hunger were poor household economic status $(\mathrm{OR}=1.76$, CI: 1.07-2.87), caregivers aged between 25-29 years and 40-54years were significantly more likely to suffer hunger. 
Table 4: Distribution of Household hunger and relationship with household economic status and background characteristics of caregivers

Caregiver characteristics HOUSEHOLD HUNGER OR (95\% CI)

\begin{tabular}{|c|c|c|c|c|}
\hline & Present & Absent & unadjusted & Adjusted \\
\hline \multicolumn{5}{|l|}{$\begin{array}{l}\text { Household economic } \\
\text { status }\end{array}$} \\
\hline Good (ref) & $306(84.8)$ & $55(15.2)$ & 1.00 & 1.00 \\
\hline Poor & $272(88.9)$ & $34(11.1)$ & $1.76(1.07-2.89)^{*}$ & $1.76(1.07-2.87)^{*}$ \\
\hline \multicolumn{5}{|l|}{ Sex of caregiver } \\
\hline Male (ref) & $287(83.2)$ & $58(16.8)$ & 1.00 & 1.00 \\
\hline Female & $815(88.0)$ & $111(12.0)$ & $1.74(0.97-3.13)$ & $1.69(0.95-3.00)$ \\
\hline \multicolumn{5}{|l|}{ Age of caregiver } \\
\hline$\leq 24$ (ref) & $38(77.6)$ & $11(22.4)$ & 1.00 & 1.00 \\
\hline $25-29$ & $117(85.4)$ & $20(14.6)$ & $3.44(0.98-12.10)^{*}$ & $3.56(1.03-12.37)^{*}$ \\
\hline $30-34$ & $175(82.9)$ & $36(17.1)$ & $2.13(0.70-6.44)$ & $2.10(0.70-6.31)$ \\
\hline $35-39$ & $170(86.7)$ & $26(13.3)$ & $2.84(0.90-8.98)$ & $2.82(0.91-8.71)$ \\
\hline $40-44$ & $165(89.2)$ & $20(10.8)$ & $4.71(1.35-16.38)^{*}$ & $4.03(1.20-13.47)^{*}$ \\
\hline $45-49$ & $109(91.6)$ & $10(8.4)$ & $5.37(1.41-20.46)^{*}$ & $5.23(1.41-19.38)^{*}$ \\
\hline $50-54$ & $110(95.7)$ & $5(4.3)$ & $5.64(1.27-25.12)^{*}$ & $5.38(1.26-23.02)^{*}$ \\
\hline $55-59$ & $66(91.7)$ & $6(8.3)$ & $2.34(0.59-9.28)$ & $2.37(0.62-9.11)$ \\
\hline $60+$ & $152(81.7)$ & $34(18.3)$ & $1.42(0.40-5.10)$ & $1.50(0.45-4.98)$ \\
\hline \multicolumn{5}{|l|}{$\begin{array}{l}\text { Highest level of } \\
\text { education }\end{array}$} \\
\hline $\begin{array}{l}\text { Never attended school } \\
\text { (ref) }\end{array}$ & $238(88.8)$ & $30(11.2)$ & 1.00 & 1.00 \\
\hline Quranic education & $30(88.2)$ & $4(11.8)$ & $0.91(0.09-8.52)$ & $0.93(0.10-8.42)$ \\
\hline Primary & $328(89.6)$ & $38(10.4)$ & $0.68(0.29-1.58)$ & $0.64(0.28-1.47)$ \\
\hline Secondary & $466(84.3)$ & $87(15.7)$ & $0.60(0.13-2.83)$ & $0.42(0.17-1.06)$ \\
\hline Tertiary & $36(78.3)$ & $10(21.7)$ & $0.47(0.18-1.20)$ & $0.60(0.13-2.68)$ \\
\hline \multicolumn{5}{|c|}{ Duration of stay in residence(years) } \\
\hline 0-9 (ref) & $535(86.7)$ & $82(13.3)$ & 1.00 & - \\
\hline $10-19$ & $296(86.5)$ & $46(13.5)$ & $0.89(0.49-1.59)$ & - \\
\hline $20-29$ & $131(84.5)$ & $24(15.5)$ & $0.73(0.34-1.58)$ & - \\
\hline $30-39$ & $68(88.3)$ & $9(11.7)$ & $0.81(0.29-2.31)$ & - \\
\hline $40+$ & $72(90.0)$ & $8(10.0)$ & $2.60(0.65-10.42)$ & - \\
\hline \multicolumn{5}{|l|}{ Literacy status } \\
\hline Cannot read at all (ref) & $478(89.2)$ & $58(10.8)$ & 1.00 & 1.00 \\
\hline $\begin{array}{l}\text { Able to read parts of a } \\
\text { sent }\end{array}$ & $297(88.7)$ & $38(11.3)$ & $1.53(0.72-3.29)$ & $1.67(0.79-3.52)$ \\
\hline $\begin{array}{l}\text { Able to read whole } \\
\text { sentence }\end{array}$ & $297(81.6)$ & $67(18.4)$ & $0.85(0.39-1.83)$ & $0.90(0.43-1.88)$ \\
\hline No card with language & $18(85.7)$ & $3(14.3)$ & $1.90(0.22-16.85)$ & $2.29(0.26-19.77)$ \\
\hline Blind/Virtual Impaired & $4(57.1)$ & $3(42.9)$ & $0.12(0.01-1.03)^{*}$ & $0.14(0.02-1.09)$ \\
\hline \multicolumn{5}{|l|}{ Marital status } \\
\hline Married (ref) & $563(83.8)$ & $109(16.2)$ & 1.00 & 1.00 \\
\hline Cohabiting & $95(92.2)$ & $8(7.8)$ & $3.42(0.97-12.05)^{*}$ & $3.31(0.95-11.57)$ \\
\hline Never married & $32(97.0)$ & $1(3.0)$ & $5.14(0.63-41.87)$ & $4.96(0.62-39.80)$ \\
\hline Divorced/separated & $86(90.5)$ & $9(9.5)$ & $1.23(0.47-3.22)$ & $1.15(0.45-2.98)$ \\
\hline Widowed & $326(88.6)$ & $42(11.4)$ & $0.84(0.45-1.57)$ & $0.89(0.48-1.65)$ \\
\hline \multicolumn{5}{|l|}{ Religion } \\
\hline No religion (ref) & $1(100.0)$ & $0(0.0)$ & 1.00 & \\
\hline Christianity & $607(85.9)$ & $100(14.1)$ & $0.76(0.46-1.25)$ & - \\
\hline Islam & $492(88.0)$ & $67(12.0)$ & - & - \\
\hline Traditional & $2(66.7)$ & $1(33.3)$ & - & - \\
\hline
\end{tabular}

\section{Discussion}

The finding of a high proportion of OVC caregivers in the elderly age-group of 60 years and above is of great concern. This is because these caregivers are most likely to be the grandparents of these OVC who on their own are most likely to need health care and other social welfare services. So for them to look after OVC may likely be a double burden. However, the finding is similar to 
what operates in the Ugandan population where majority of caregivers were 50 years and above with serious implications on their health and wellbeing ${ }^{13}$.

The fact that most caregivers were able to pay for food expenses incurred whereas a high number of them could not pay for expenses incurred on education would suggest the priority of caregiver is food survival. There is a general belief in the Nigeria culture that with hunger no activity can be undertaken successfully ${ }^{15}$. this underscores the poor earning capacity whose income could cater for food in the main. Also, that caregivers who had at least a secondary school education were less likely to suffer from hunger suggests education is more likely to increase the earning power of the caregivers. Education buys awareness and with education the chances of learning skills would improve thus increasing the chances of money making ${ }^{5}$.

In this study, a high level of household hunger observed in most households is bound to have diverse negative consequences on the nutrition status, cognitive development, and general wellbeing of younger OVC especially those under- five years of age $\mathrm{e}^{5,7}$. In fact the older OVC may be exposed to all sorts of harassment, labor and exploitation as a result of food deprivation ${ }^{9,14}$. Poor household economic status is a strong predictor of household hunger. Caregivers whoare vulnerable than males. This is consistent with other study and this has been linked to the fact that female have less access to money ${ }^{20}$. The poor household economic status and the consequence on household hunger found has some implications for OVC programmes in Nigeria. First, it provides empirical evidence for the paradigm shift to family oriented OVC programming which aimed to strengthen households economically. Secondly, there is need to pay attention to the increasing proportion of elderly OVC caregivers which may be due to the strong extended family ties in the Nigerian setting as this category of caregivers may not be easily trained to learn any skill or trade. Therefore, it would be worthwhile to devise innovative approaches to cater for OVC whose primary caregivers are older persons. Hunger was more rampant in households where the caregiver was single, divorced or separated. These types of households need to be identified and specially targeted for support and interventions to enhance the standard of living of OVC in such households. One limitation of this study is the small sample size in some of the categories of the variables but this does not affect the interpretation of the results.

\section{Conclusion}

This study found a high level of hunger in OVC households and this is strongly associated with poor household economic status, old age of caregiver and marital status (in particular single parents occasioned either by divorce/separation or widowhood). Strengthening of household economy could have high positive effect on the food security of households and the provision of other social services for the OVC. Also the characteristics of OVC caregivers should be put into consideration in the design of OVC in any intervention programs in these LGAs in Lagos state.

\section{References}

1. Federal Ministry of Women Affairs and Social Development Nigeria research situation analysis on orphans and other vulnerable children. Boston University Center for Global Health and Development, 2009.

2. FMoH. National HIV/AIDS and Reproductive Health and Serological Survey (NARHS Plus) 2012. Abuja, Nigeria: 2013.

3. National Agency for the Conrol of AIDS. Global AIDS Response Country Progress Report, 2015. Abuja, Nigeria: NACA, 2015.

4. PEPFAR. The United State President's Emergency Plan for AIDS Relief (PEPFAR) Guidance for Orphans and Vulnerable Children Programming. Washington DC: PEPFAR, 2012.

5. Olanrewaju AD, Jeffery C, Crossland N, et al. Access to Education for Orphans and Vulnerable Children in Uganda: A Multi-District, Cross-Sectional Study Using Lot Quality Assurance Sampling from 2011 to 2013. PLoS One. 2015;10(7):e0132905.

6. Kembo J. Social and economic consequences of HIV and AIDS on children: case study of a high- density community in Harare, Zimbabwe. Sahara J. 2010;7(4):39-46. 7. Goodman ML, Seidel SE, Kaberia R, et al. How can we improve healthcare access and general self-rated health among orphans and vulnerable children? Findings from a Kenyan cross-sectional study. Int J Public Health. 2015;60(5):589-597.

8. Amoako Johnson F, Padmadas SS, Smith PW. Orphanhood and vulnerability: a conduit to poor child health outcomes in Rwanda. AIDS Care. 2010;22(3):314-323.

9. Nsagha DS, Bissek AC, Nsagha SM, et al. The Burden of Orphans and Vulnerable Children Due to HIV/ AIDS in Cameroon. Open AIDS J. 2012;6:245-258.

10. National Population Commission [Nigeria]. Nigeria Demographic and Health Survey 2013. National Population Commission and ORC Macro International, Calverton MD, 2014. 
11. Tagurum YO, Chirdan OO, Bello DA, et al. Situational analysis of orphans and vulnerable children in urban and rural communities of Plateau State. Ann Afr Med. 2015;14(1):18-24.

12. Measure Evaluation. PEPFAR Essential Survey Indicators: A supplement to the Orphans and Vulnerable Children Survey Tools - Guide. 2014. MS-14-90. 2014.

13. Ssengonzi R. The impact of HIV/AIDS on the living arrangements and well-being of elderly caregivers in rural Uganda. AIDS Care. 2009;21(3):309-314.

14. Biemba G, Walker ME, Simon J. Nigeria Research Situation Analysis on Orphans and other Vulnerable Children. Boston University: USAID, 2009.

15. Maes KC, Shifferaw S, Hadley C, et al. Volunteer home-based HIV/AIDS care and food crisis in Addis Ababa, Ethiopia: sustainability in the face of chronic food insecurity. Health Policy Plan. 2011;26(1):43-52.

16. Parker DC, Jacobsen KH, Komwa MK. A qualita- tive study of the impact of HIV/AIDS on agricultural households in Southeastern Uganda. Int J Environ Res Public Health. 2009;6(8):2113- 2138.

17. Rivers J, Mason JB, Rose DD, et al. The impact of orphanhood on food security in the high-HIV context of Blantyre, Malawi. Food Nutr Bull. 2010;31(3 Suppl):S264-271.

18. Twine W, Hunter LM. Adult mortality and household food security in rural South Africa: Does AIDS represent a unique mortality shock? Dev South Afr. 2011;28(4):431-444.

19. Weiser SD, Tsai AC, Gupta R, et al. Food insecurity is associated with morbidity and patterns of healthcare utilization among HIV-infected individuals in a resource-poor setting. Aids. 2012;26(1):67-75.

20. Oginni A, Ahonsi B, Ukwuije F (2013). Are female-headed households typically poorer than male-headed households in Nigeria? Journal of Socio-Economics 45:132-137. 